
3 Research Square
Preprints are preliminary reports that have not undergone peer review.
They should not be considered conclusive, used to inform clinical practice, or referenced by the media as validated information.

\title{
Experimental Study On The Root-Soil Friction Mechanical of Typical Grasses With Soil Moisture In Purple Soil Bunds
}

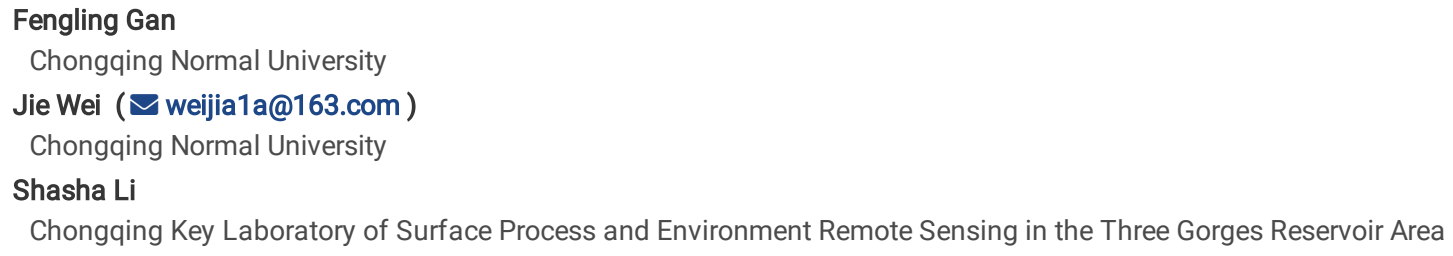

\section{Research Article}

Keywords: Purple soil bunds, Root-soil interface, Direct shear friction characteristics, Drawing function properties, Three Gorges Reservoir area

Posted Date: September 17th, 2021

DOI: https://doi.org/10.21203/rs.3.rs-794503/v1

License: () (1) This work is licensed under a Creative Commons Attribution 4.0 International License. Read Full License 


\section{Abstract}

[Aims] Bunds composed of plants with strong root systems have become one of the most important soil conservation measures for controlling soil erosion on sloping farmlands in the Three Gorges Reservoir area. In order to measure the friction characteristics of the root-soil interfaces to screen grasses for use in bunds to provide optimal soil bund protection.

[Methods] The influences of interface, soil moisture and vertical load were examined by using direct shear friction and pull-out friction tests in the study.

[Results] The results support the following conclusions. i) Friction characteristics were lower at interfaces in bulk soils than at root-soil interfaces. Direct friction characteristics were higher at the root-soil interface for goosegrass than other plants tested in this study. ii) The roots of grasses can substantially improve the soil shear strength under conditions of low (5\%) and high soil moisture (25\%). The relationships between friction characteristics and soil moisture can be described by binomial functions. iii) The constitutive relationship between the shear strength at the root-soil interface and vertical load can be described by a hyperbolic model that satisfies the Mohr-Coulomb criterion. The maximum pulling resistance was in the following order: goosegrass > barnyard grass > crabgrass.

[Conclusions] Among the three grasses tested, the goosegrass root system has a highest resistance to deformation capability for soil conservation. These results can be used as references for understanding and controlling the friction characteristics and collapse of soil bunds in the Three Gorges Reservoir area.

\section{Introduction}

Purple soil in sloping farmland is the main support of agricultural production in the Three Gorges Reservoir area, and it accounts for $78 \%$ of the total cultivated land in this area (Cui et al., 2011; Chen et al., 2016; Zhang et al., 2018). The average amount of annual soil erosion in the Three Gorges Reservoir area is estimated to be $1.5 \times 10^{8} \mathrm{t}$, and the reservoir sediment reaches approximately $4 \times 10^{7} \mathrm{t}$, more than $60 \%$ of which comes from sloping farmland (Sun et al., 2019 ). The sloping farmland in this area is characterized by high losses of water and soil loss, shallow topsoil layer and serious agricultural pollution. Hence, detailed measurements of soil and water are necessary for conservation and to guarantee the ecological safety of the Three Gorges Reservoir area. Bunds are an important soil and water conservation measure currently used to conserve purple soil and water in sloping farmland, and they occupy more than $15 \%$ of the cultivated area (Amare et al., 2014; Jemberu et al., 2017; Wei et al., 2018). The main functions of bunds in soil conservation are to maintain gravitational stability and decrease soil erosion on farmland slopes, and thereby prevent farmland collapse and control sediment loss (Raes et al., 2007; Oliver et al., 2018). Stone bunds and soil bunds are extensively used for farmland renovation in the Three Gorges Reservoir area. Stone bunds involve high construction costs and labour input, and they are not popular in the countryside (Andreas et al., 2017). However, in contrast to stone bunds, soil bunds have better water and soil conservation capabilities and require a lower cost and smaller labour force; thus, soil bunds are preferred by farmers. Soil bunds are widely used in controlling soil erosion of sloping cultivated land and farmland construction projects in the Three Gorges Reservoir area (Walle et al., 2017). However, the mechanism by which soil bunds stabilize cultivated land is not clear. Thus, it has become more urgent to have a complete understanding of the stability characteristics and stabilizing mechanism of purple soil bunds in the Three Gorges Reservoir area.

Using vegetation to protect slopes is an efficient technique for the stabilization of slopes with shallow soil layers and, initially, without plant roots (Yves et al., 2018; Borjana et al., 2020). Interaction between root systems and soil particles can improve not only protect soil from erosion but also stabilize slopes. There are two main research models for investigating the mechanical mechanism of root-soil. The first model assumes that the root system and soil form a root-soil complex (Yang et al., 2016). The internal forces at a root-soil interface have some impact on the physical and chemical properties of the root system and soil but are not directly applied in calculations of stress and strain. Thus, most studies use a shear test method based on this model (Emilio et al., 2019; Yao et al., 2020). For example, Binh et al. (2018), through triaxial tests, showed that the shear strength and residual strength of the root-soil interface were much higher than those of the bare control soil and indicated that the soil strength can be efficiently improved by the presence of a root system in soil. The second research model considers the root system and soil as entirely separate, and treated them as two component of the same material (Gregoire et al., 2017). This model uses pull-out friction tests to study the interaction mechanism at the root-soil interface. Harsh et al. (2016) researched the root tensile strength of three shrub species in the Italian Apennines, analysed the slope stability on steep clay hills, and concluded that the regression relationship between tensile strength and root diameter was a quadratic polynomial. Related studies have indicated that plant roots effectively improve the stability of rock mass slopes because fine roots have a reinforcing effect, stout vertical roots act as anchors and stout horizontal roots stretch (Benedetta et al., 2020). Moreover, surface friction of the root-soil interface enables the plant root system to provide soil reinforcing, anchoring and stretching (Lise et al., 2018). Hence, it is necessary to analyse the mechanism that enables plant roots to reinforce soil, and the focus should be put on the friction characteristics of the root-soil interface.

The friction characteristics of the root-soil interface in purple soil bunds have received little attention thus far. Few studies have considered the contributions of friction characteristics to bund stability and the impacts of changes in the water content on the friction characteristics of the root-soil interfaces in purple soil bunds. Most studies have focused on the shear strength of soil, which is an important parameter of soil bund stability (Jaime et al., 2017; Vietha et al., 2020). Cohesion and internal friction angle are often used to analyse shear strength. Factors that influence the shear strength of soil, such as the soil dry density, soil water content, plant root system and soil grain size distribution, have been explored through triaxial compression and direct shear tests. For example, Wang et al. (2015) proposed that soil cohesion and internal friction angle are closely related to soil water content, decreasing linearly as water content increases. Havaee et al. (2015) found that soil cohesion increases with increasing dry density, while the internal friction angle changes slightly with increasing dry density at a given soil moisture. The above research has mainly explored the characteristics of shear strength in purple soil bunds and has obtained some results (Wang et al., 2012; Adimassu et al., 2014). However, both the direct shear friction and drawing friction can affect the stability of purple soil bunds. The drawing friction of the root system can increase the soil shear strength, improving the soil stability. A systematic study of the friction characteristics of the root-soil interface in purple soil bunds is lacking. 
An increase in soil moisture can directly decrease the shear strength of a root-soil interface and even promote soil collapse (Zhang et al., 2010; Apiniti et al., 2018), which is the main factor influencing friction properties of root-soil interfaces and stability of soil bunds. For example, Wei et al. (2018) carried out a study on purple soil bunds to analyse the impact of soil moisture and dry density on shear strength. Their results showed that the influence of soil moisture on bund stability was greater than that of dry density. Moreover, in purple soil bunds, plants with developed root systems can not only increase soil bund shear strength but also strengthen surface soil. Thus, it is necessary to determine the surface friction characteristics of the root-soil interface in purple soil bunds.

Taking purple soil bunds as an example, the present study makes an initial effort to study the direct shear friction characteristics and drawing friction properties of root-soil interfaces by performing direct shear friction tests and pull-out friction tests. The goals of the present study are to 1) explore the mechanisms by which changes in soil moisture influence the direct shear friction characteristics and drawing friction properties of the root-soil interface, and 2) determine the best choice among typical grasses for protection of purple soil and slopes by soil bunds. These results are significant for studying the mechanical mechanism at the root-soil interface and helping to prevent and control purple soil bund collapse in China.

\section{Materials And Methods Study area}

The study area is located in the Xiema watershed in the Beibei District of Chongqing Municipality, China. The watershed is part of the Jialing River basin, which extends from $29^{\circ} 27^{\prime} 08^{\prime \prime}$ to $30^{\circ} 05^{\prime} 08^{\prime \prime} \mathrm{N}$ and from $106^{\circ} 18^{\prime} 02^{\prime \prime} \mathrm{E}$ to $106^{\circ} 40^{\prime} 57^{\prime \prime} \mathrm{E}$; it was selected because it is representative of the Beibei District of the Three Gorges Reservoir Region with respect to geologic features, soil crops and climatic characteristics. The study area has an average annual rainfall of approximately $1105.4 \mathrm{~mm}$ and an average annual temperature of $18.3^{\circ} \mathrm{C}$, which is a subtropical humid climate.

The test soil is purple soils,which are classified as Orthic Entisols in the Chinese Soil Taxonomic System, Regosols in FAO Taxonomy or Entisols in USDA Taxonomy. A well weathered purple soil usually contains about $15 \%$ clay with $1.7 \%$ organic matter, $0.07 \%$ total nitrogen and $0.06 \%$ total phosphorus (He et al., 2007). Purple soil in sloping farmland is the main source of sediment in the Three Gorges Reservoir, and pertinent and detailed measurements are required to design an effective soil and water conservation scheme. Soil bunds can reduce the erosivity and volume of runoff and sediment loss of purple soil on sloping farmland. Based on a field investigation, the dominant angle of purple soil bunds range from $56^{\circ}$ to $90^{\circ}$, the heights of the bunds are between 55 and $220 \mathrm{~cm}$, and the bund widths range from 30 to $80 \mathrm{~cm}$. In addition, soil moisture in the study area ranged from $1.87-28.78 \%$ during the dry season and rainy seasons, respectively.

\section{Soil sample preparation}

Field experiments were conducted from July to September 2019 at typical purple soil bunds. Based on a field survey, three typical grasses (including crabgrass, barnyard grass and goosegrass) and bare control soil were collected in the study area. The soil sampling points were on an $S$-shaped curve within each soil bund, and more than $85 \%$ of each bund was covered by grasses. Sixteen plant species were collected vertically from soil bund depths from 20 to 60 $\mathrm{cm}$, and surface soil (to $20 \mathrm{~cm}$ ) was removed to obtain samples with consistent root distribution in the vertical direction. There were three replicates of each layer and 144 soil samples in total. The diameters, lengths and fractal dimensions of the roots of these three typical grasses were collected as reference data for the remoulded root-soil interfaces in the present study (Fig. 1).

In addition, $500 \mathrm{~g}$ loose soil samples were collected from each sample point, and used to measure the soil physical-chemical properties and to make the remoulded soils. The soil particle distribution was obtained by a laser particle size analyser. The physical-chemical properties of the experimental soils in the soil bunds were as follows: $10.77 \%$ clay $(<0.002 \mathrm{~mm}), 69.47 \%$ silt $(0.002-0.02 \mathrm{~mm}), 19.76 \%$ sand $(0.02-2.00 \mathrm{~mm}), 1.49 \% \mathrm{SOM}$ and $6.14 \mathrm{pH}$. Meanwhile, the corresponding root systems were pulled out and sheared at root junctions. The root samples were wrapped with plastic sheets and kept in a low-temperature environment at 4 degrees Celsius.

\section{Preparation of a remoulded root-soil composite}

Based on the field survey, all the root diameters of crabgrass, barnyard grass and goosegrass were less than $1.0 \mathrm{~mm}$, so roots were selected in the 0 to $1.0 \mathrm{~mm}$ range for consistency. The roots were divided into two categories: diameter class $\nabla$ of $0-0.5 \mathrm{~mm}$ and diameter class $\nabla$ of $0.5-1.0 \mathrm{~mm}$. The ratio of root area within the cutting ring was less than $2.83 \%$ according to the mean soil root content of the undisturbed root-soil composite. To ensure that the ratio of root area

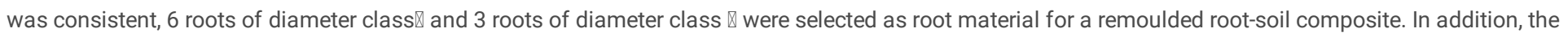
soil material of the remoulded root-soil composite was collected from the sampling sites of the soil bunds. The soil samples were air-dried and sifted through a $2 \mathrm{~mm}$ sieve. The air-dried moisture content of the soil samples was determined ( $5.1 \pm 0.48 \%)$, and the samples were sealed in a box. The remoulded root-soil composite was made according to the standards of geotechnical test methods in China.

Meanwhile, according to the mean soil moisture of soil bunds in the dry and rainy seasons, the soil moisture was set to $5 \%, 10 \%, 15 \%, 20 \%$ and $25 \%$. The mean soil dry density was fixed at $1.35 \mathrm{~g} \cdot \mathrm{cm}^{-3}$ according to the mean soil density of soil bunds in the field. Finally, the selected test root and soil samples were compacted layer by layer in the cutting ring to prevent damaging the root system until the remoulded root-soil composite reached the experimental soil moisture content and soil dry density conditions. Each soil sample was analyzed in triplicate.

\section{Direct shear friction test}

The direct shear friction test was conducted with a fully automatic quadruple shear device made by Nanjing Zhilong Technology Development, China. The experimental device includes a controlling system, water container, pressure chamber, confining pressure sensor and testing machine. The cross section of the shear box is circular and has an area of $30 \mathrm{~cm}^{2}$. The experimental device can apply a vertical load from 0 to $400 \mathrm{kPa}$, the horizontal shear force can reach 1.2 $\mathrm{kN}$, and the shear rate can reach $5 \mathrm{~mm} \cdot \mathrm{min}^{-1}$. The experimental data can be analysed and displayed on a computer in real time (Fig. 2).

Page $3 / 11$ 
A root system with a length greater than $6 \mathrm{~cm}$ was selected as the representative root sample. The same diameter of root was pasted to a porous stone (6.1 $\mathrm{cm}$ diameter and $0.9 \mathrm{~cm}$ thick) with glue, with the roots parallel. The root samples were kept at 4 degrees Celsius. The porous stone and experimental root samples were placed under the shear box, with the root axis parallel to the shear direction, and the soil sample was placed in the shear box. A similar method was used to prepare the bare control soil samples for testing. For each sample, the shear rate was fixed at $0.8 \mathrm{~mm}^{\mathrm{min}}{ }^{-1}$, and the vertical load was set to 25 , $50,75,100$ and $150 \mathrm{kPa}$. The direct shear strength parameters, such as cohesion and internal friction angle, can be calculated based on the Coulomb force law.

\section{Pull-out friction test}

The pull-out friction test was conducted with an electronic tension tester (LDS-5A). This experimental device includes a mainframe, tensile testing jigs, stepper motor, stepping motor driver, high precision deceleration system, strain gauge load cell, computer and ink-jet printer. The accurately measured test force ranges from 200 to $5000 \mathrm{~N}$, the maximum test force can reach $5000 \mathrm{~N}$, the control range of the displacement speed is between $5 \mathrm{and}^{2} 200 \mathrm{~mm} \cdot \mathrm{min}^{-1}$, and the effective stretching schedule can reach $860 \mathrm{~mm}$. The pull-out strength can be automatically displayed on the computer in real time (Fig. 3).

Bare roots longer than $8 \mathrm{~cm}$ were selected as experimental roots, and the remoulded soil was like that used in the direct shear friction test. The remoulded soil was added in two parts to a homemade container $(6.1 \mathrm{~cm}$ inner diameter and $2.0 \mathrm{~cm}$ high), and the middle of the homemade container had a round hole with a diameter of $2 \mathrm{~mm}$. After the first addition of remoulded soil, the remoulded soil was compacted to a level slightly higher than half the diameter of the circular hole, and the plant root passed through the circular hole through the exposed end of the clip. After all the remoulded soil was added to the container, a lid was placed on top to guarantee that the experimental roots were in the centre of the circular hole and avoid friction between the experimental roots and the edge of the circular hole. Finally, the root-soil composite specimen was fixed in the jig of a universal tension machine. During the tests, the loading speed was fixed at $10 \mathrm{~mm} \cdot \mathrm{min}^{-1}$.

\section{Data analysis}

The experimental data was plotted by Excel 2010. One-way ANOVA analysis and regression analyses were performed by SPSS $19.0, \mathrm{P}<0.01$ was considered extremely significant and $\mathrm{P}<0.05$ was considered significant. All experimental data were collected and processed automatically by the instrument used to test the soil samples.

\section{Results}

\section{Friction characteristics at different interfaces}

Variations in the root-soil friction interface cause roots to grow in different ways and develop significantly different friction characteristics. Table 1 shows the root-soil friction characteristics of different sample interfaces for the pure purple soil bunds and the purple soil bunds with different typical grasses. The friction angles and friction coefficients of the soil-soil interfaces differed significantly $(P<0.05)$, and were less than those of the root-soil. Meanwhile, the friction angle and friction coefficient of different root-soil interfaces were in the following order: goosegrass > crabgrass > barnyard grass. Moreover, the cohesive stress of the root-soil interface of goosegrass was obviously different from that of the other root-soil interfaces and soil-soil interfaces $(P<0.05)$, and the cohesive stress of the samples with different typical grass roots were in the following order: goosegrass < crabgrass < barnyard grass. In general, the friction angle and friction coefficient were maximum, and the cohesion stress was minimum at the root-soil interfaces of goosegrass. It can be concluded that goosegrass has the highest direct shear friction characteristics, followed by crabgrass, and barnyard grass, which has the lowest direct shear friction characteristics.

\section{Friction characteristics of different soil moistures}

Soil moisture is an important control factor that affects the friction characteristics. The soil moisture was taken as an independent variable, and the corresponding friction characteristics (friction angle, cohesive stress and friction coefficient) were taken as dependent variables for a regression analysis and multi-model fitting. The results of the fitting are shown in Fig. 4 . The most significant correlations observed were between the friction characteristics and soil moisture for the soil-soil and root-soil interfaces $(P<0.01)$, which could be described by binomial functions.

However, very large differences in the friction characteristics of the soil-soil and root-soil interfaces were observed for the samples with grass roots at different soil moisture levels. For the soil-soil interfaces, the friction angle and friction coefficient first decreased and then increased with increasing soil moisture, and the minimum value occurred at soil moisture levels of $32.04 \%$ and $27.61 \%$. The cohesive stress showed an inverse trend, with the maximum value occurring at a soil moisture of $15.98 \%$. For the three typical grass roots, all friction characteristics first increased and then decreased with increasing soil moisture, and the maximum value was found at a soil moisture of approximately $15 \%$.

\section{Relationship between vertical load and shear strength of root-soil interfaces}

According to classical soil mechanics theory, the relationship between soil shear strength and vertical load should satisfy the Mohr-Coulomb criterion. In the present study, the relationship between the shear strength of the root-soil interface and vertical load was consistent with the Mohr-Coulomb criterion under the condition of $15 \%$ soil moisture. Fig. 5 shows the relationship between the shear strength and vertical load in purple soil bunds with typical grasses and soil. The soil shear damage resistance increased with the vertical load; a significant positive correlation was found between the shear strength and vertical load, and the fitting determination coefficients were larger than 0.90 . The shear relationships of these three typical grass root-soil interfaces agreed with MohrCoulomb theory, like that of the soil-soil interfaces. Thus, the cohesion, internal friction angle and friction coefficient of a root-soil interface can be calculated based on the Mohr-Coulomb theory. 
Table 2 shows the results of numerical simulations of direct friction tests for interfaces at $15 \%$ soil moisture. The numerical simulation results were close to the experimental results. By comparing the relative error of the numerical simulation and experimental results for the different frictional interfaces, the mean values of the absolute relative error were as follows: goosegrass $(5.99 \%)<$ barnyard grass $(10.54 \%)<$ soil-soil $(11.75 \%)<$ crabgrass $(14.36 \%)$.

\section{Relationship between pulling resistance and root displacement}

Fig.6 shows the relationship between pulling resistance and root displacement at high and low soil moisture levels for the purple purple soil bunds, with and without different typical grasses. The curves for pulling resistance and root displacement are basically the same, regardless of the soil moisture. The characteristics of these curves were summarized as follows: 1) In the early stages of the test, when the roots were under the action of the drawing force, there was static root-soil friction during the relatively small amount of root displacement. The pulling resistance of crabgrass, barnyard grass and goosegrass was $0 \sim 0.2 \mathrm{~N}$, and the maximum static friction force was $0.2 \mathrm{~N}$. 2) As the root system was pulled out of the direct shear box, the pulling resistance increased nonlinear with increasing of root displacement until the pulling resistance reached the maximum friction force. 3) The maximum root-soil friction force of crabgrass, barnyard grass and goosegrass remained relatively constant for root displacements of 2.91 12.97 mm, 5.08 18.94 mm and 1.11 13.97 mm under the conditions of high and low soil moisture, respectively. 4) A downward trend in the pulling resistance of crabgrass, barnyard grass and goosegrass began when the root displacement was greater than 12.97, 18.94 and $13.97 \mathrm{~mm}$, and the pulling resistance of these three grasses fell to a certain value until the end of the pull-out friction test. In addition, the maximum pulling resistance at high soil moisture was much greater than that at low soil moisture, and the maximum pulling resistance of the studied grasses as follows: goosegrass > barnyard grass > crabgrass.

\section{Analysis of root-soil friction characteristics and influencing factors}

To further compare the effects of soil moisture, vertical load and interface type on root-soil friction, we used principal component analysis (PCA) to identify the main influences on root-soil fiction parameters (cohesive stress, friction angle, friction coefficient and shear strength) (Fig. 7). The first PCS had the highest loading effect and explained of $45.65 \%$ of the cumulative (total) variance, which was the predominant factor for changes in the studied variables. The variables of PC1 consisted of interface type, soil moisture, friction coefficient, friction angle and cohesive stress. The second PC included vertical load and shear strength. PC1 and PC2 explained $77.20 \%$ of the total variance. Therefore, the relationship between the root-soil friction and influencing factor can be given by this two-dimensional sequence diagram. The interface type and vertical load had a positive relation with the friction coefficient, friction angle and shear strength, while the soil moisture had a negative correlation with most of the root-soil friction parameters. In addition, the influence of the variables on the root-soil friction characteristics increased in the following order: interface type > soil moisture > vertical load.

\section{Discussion}

\section{Effect of friction interfaces on friction characteristics}

The main influencing factors on the direct shear friction of the root-soil interface include the vertical load, dry density, soil moisture and vegetation type. In the present study, the root-soil cohesions of goosegrass exhibited significant differences with crabgrass and barnyard grass $(P<0.05)$, and the root-soil cohesions of crabgrass and barnyard grass were much higher than those of goosegrass. It can be concluded that the root surfaces of crabgrass and barnyard grass absorb soil particles more strongly, resulting in a situation that does not differ significantly from that of the bare control soil $(P>0.05)$. In general, the low root-soil cohesion of these three typical grasses indicated that there was no correlation between root-soil cohesion and the improvement in soil shear resistance at different soil moisture levels. These results are like those obtained by Wei et al. (2018) in an experimental study and Tian et al. (2015) in a theoretical study. This similarity may be because there is incomplete contact between the root and soil in the unconsolidated shear specimens; hence, the rootsoil cohesion exhibited "false cohesion" for the frictional strength of the root-soil interface under vertical loading.

Meanwhile, there were striking differences in the friction angle and friction coefficient between the soil-soil and root-soil interfaces $(P<0.05)$, and the soil-soil interfaces had the lowest friction angle and friction coefficient among the different friction interfaces. This is because the frictional force of the soil-soil interfaces depends on the blocking action of soil particles, while for the root-soil interface, the root surface roughness is the element that most influences the frictional force at the root-soil interface. The greater the root surface roughness and/or the larger the root surface area, the greater the contact area between the root and soil, and thus, the larger the root-soil frictional force. Hence, it can be concluded that the goosegrass root-soil interface had a larger frictional force with greater root surface roughness than the other two typical root-soil interfaces.

Furthermore, the correlation coefficients of the shear strength and vertical load in the root-soil interfaces of goosegrass were higher than those in the soil with the other two typical grasses and those in the bare control soil. Related studies have indicated that the response of the shear strength of a root-soil interface to a vertical load varied greatly for different root samples and root surface roughnesses for the same plant and diameter class, while the shear strengths of the bare control soil samples were tightly distributed. Meanwhile, there were considerable differences in shear strength among the samples with the three typical grasses and different soil moistures, but the shear strengths of these samples were greater than that of the bare control soil. Thus, the root system did not fully utilize its friction effects under a low vertical load; this finding is similar to that of Baets et al. (2008). In addition, the frictional resistance of the root-soil interface tended to increase nonlinearly with increasing depth of the root system. The rate of increase in the frictional resistance of the root-soil interface was larger when the depth of the root system was shallower, while the rate of increase in the frictional resistance of the root-soil interface was smaller when the depth of the root system was deeper. These results are slightly different from those of Xing et al. (2010), who found that the frictional resistance of the rootsoil interface increased as the vertical load increased. This difference may be because in our study, the interval of the vertical loading is consistent, while in the Xing et al. (2010) study, the lower interval of the vertical loading is smaller than the higher interval of the vertical loading, which led the change rate of the frictional resistance of the root-soil interface under the higher vertical load to be much higher than that under the lower vertical load.

Effect of soil moisture on friction characteristics 
Soil moisture is one of the most important factors affecting the friction characteristics. In the present study, the friction angle, cohesive stress and friction coefficient of the root-soil interface and soil-soil interface followed a binomial distribution with increasing soil moisture. It can be concluded that the increase in soil moisture content is beneficial for the root-soil anchorage effect, although when the soil moisture increased to a certain range (15\% 20\%), the root-soil anchorage effect was reduced. These results are like those of the experimental studies of Li et al. (2013b) and Zhao et al (2021). The reason for this phenomenon is that when the soil moisture increased, the water films more rapidly on the surfaces of the soil particles and roots; hence, the degree of blocking between the root and soil particles decreased. At the same time, the distance between the soil particles and root system increased, which decreased the connection strength of the root-soil interface. All these factors led to a first increasing and then decreasing trend in the internal friction angle of the root-soil interface under the condition of an unchanged extrinsic effective pressure (Wei et al., 2016). In addition, for the soil moisture levels of $5 \%$ and $25 \%$, the cohesive stress of the root-soil interface was significantly lower than those under the other experimental conditions $(P<0.05)$. Therefore, the root system could significantly improve the soil shear strength in the dry and rainy seasons, and it can be further speculated that seasonal variation has a significant influence on soil reinforcement by plant roots.

In addition, the drawing friction properties of root systems are crucial determinants of soil conservation for plants. The maximum pull-out resistance and pull-out strength are two important characteristic indexes of the mechanical characteristics of roots. When a root system is pulled out by an external force, there are two main failure modes: tensile failure and friction failure. In the present study, the process curve of friction failure (displacement vs. pull-out force curve) can be divided into three stages: first sharp decline, second sharp decline and slow decline. At the initial stage of pull-out, the displacement of the root system in the soil tends to zero, which means that there is sattic friction between the root and soil. When the sliding displacement ranged from $0.5 \mathrm{~mm}$ to 20 $\mathrm{mm}$, the root system started sliding when the root pulling force became greater than a certain value, and the friction of the root-soil interface changed from a static friction to sliding friction, leading to the root system being pulled out at the maximum simple root pulling capacity. As soon as the sliding displacement increased, the drawing force decreased gradually and finally stabilized. Murielle et al. (2014) indicated that the reasons for this phenomenon were as follows. At the beginning of the drawing shear, the uneven surface of the root system interlocked with soil particles, and soil particles at the contact surface lifted, separated and rotated as the drawing shear increased. At the same time, the volume of the soil changed. All of these factors require an external force. Therefore, the drawing force rapidly increased to a maximum value in an early stage of the test. Then, the shearing process continued, and the root-soil interface tended to become smooth due to the movement and rearrangement of the soil particles around the root system. Finally, the frictional resistance and drawing force gradually decreased and stabilized. The maximum pulling resistance was much higher at high soil moisture than that at low soil moisture. When the soil moisture was low, the contact between the soil particles and root systems was quite loose, and the cohesion between the soil and root system was low, leading to the low pull-out strength of the root system (Ghestem et al., 2014). With increasing soil moisture, a bound water membrane formed at the interface of the soil particles and water in the soil, and the cohesion of the root-soil interface increased under the influence of water cementation, so that the maximum static friction of the root-soil interface and root pull-out strength increased to some extent.

Overall, based on the redundancy analysis, the interface type had the greatest impact on the root-soil friction characteristics in the present study. Goosegrass, as one of the typical root-soil interfaces in purple soil bunds, has better drawing friction properties than the other two typical grasses. The root system of goosegrass improves the effectiveness of soil conservation and the degree of surface coverage and thus should be more widely used in the ecoenvironment construction of purple soil bunds for soil and water conservation. It can be concluded that goosegrass is the best choice among the three vegetation types tested in purple soil bunds for soil and slope protection. Moreover, for further research and discussion, the other soil physical-chemical properties that influence the friction characteristics of the root-soil interface should be studied to establish a scientific theoretical model of the root-soil interface in purple soil bunds.

\section{Conclusions}

Direct shear friction and pull-out friction tests were performed to analyse the surface friction characteristics at the soil-root interfaces of three typical grasses from purple soil bunds.

1. The friction characteristics were significantly lower at the soil-soil interfaces than at the root-soil interfaces $(P<0.05)$, causing the shear strength to be lower at the soil-soil interfaces than the root-soil interfaces. In addition, the direct shear friction characteristics were highest for the goosegrass root-soil interfaces.

2. Changes in soil moisture have similar effects on the friction characteristics of the soil-soil and root-soil interfaces, and the root system significantly promotes soil shear strength in dry and rainy seasons $(P<0.05)$. The relationship between the shear strength of the root-soil interface and vertical load satisfied the Mohr-Coulomb criterion.

3. The process curve of friction failure (displacement vs. pull-out force curve) can be divided into four stages: first sharp decline, second sharp decline, slow decline and stable fluctuations. The redundancy analysis results showed that the interface type and soil moisture made higher contributions than other factors to the friction characteristics of the root-soil interfaces.

In general, goosegrass is the best choice among the three vegetation types tested to protect the soil and slopes in purple soil bunds with the greater root-soil friction characteristics of the studied grasses.

\section{Declarations}

\section{Acknowledgements}

This study was financially supported by the Chongqing Talent Program (CQYC201905009), the Chongqing Education Commission (KJZD-K201800502), 
Science Fund for Distinguished Young Scholars of Chongqing (cstc2019jcyjjqX0025) and the Chongqing National Science Foundation (cstc2018jcyjAX0489). We are grateful to Dr. Chunhong Liu for her helpful comments.

\section{References}

1. Amare T, Zegeye AD, Yitaferu B, Steenhuis TS, Hurni H, Zeleke G (2014) Combined effect of soil bund with biological soil and water conservation measures in the northwestern Ethiopian highlands. Ecohydrology Hydrobiology 14:192-199

2. Andreas K, Christoph S, Stefan S, Nigus DM, Feras Z, Andreas S, Claudio Z (2017) Impact of stone bunds on temporal and spatial variability of soil physical properties: A field study from northern Ethiopia. Land Degradation Development 29:585-595

3. Adimassu Z, Mekonnen K, Yirga C, Kessler A (2014) Effect of soil bunds on run-off, soil and nutrient losses, and crop yield in the central Highlands of Ethiopia. Land Degradation Development 25:554-564

4. Apiniti JK, Natthapat RC (2018) Shear strength of interfaces between unsaturated soils and composite geotextile with polyester yarn reinforcement. Geotextiles Geomembranes 46(3):338-353

5. Baets SD, Poesen J, Reubens B, Wemans K, Baerdemaeker JD, Muys B (2008) Root tensile strength and root distribution of typical Mediterranean plant species and their contribution to soil shear strength. Plant Soil 305:207-226

6. Borjana A, Kylie JF, Megan CS, Helen B, Michelle W (2020) Dynamics in plant roots and shoots minimize stress, save energy and maintain water and nutrient uptake. New Phytol 225(3):1111-1119

7. Benedetta C, Francesca TSG, Nicola P, Barbara M (2020) Plant root penetration and growth as a mechanical inclusion problem. International Journal of Non-linear Mechanics 120:103344

8. Binh TP, Le HS, Tuan-Anh H et al (2018) Prediction of shear strength of soft soil using machine learning methods. Catena 166:181-191

9. Chen Y, He BH, Lian CX et al (2016) Study of root-soil system anti-scourability on steep slopes in the Three Gorges Reservoir Area. Acta Ecol Sin 36(16):19

10. Cui P, Ge Y (2011) Soil erosion and sediment control effects in the Three Gorges Reservoir Region, China. Journal of Resources Ecology 2(4):289-297

11. Emilio B, Gregor G, Christian L, Luca P, Roman G, Wolfgang HM (2019) Out-of-plane buckling of pantographic fabrics in displacement-controlled shear tests: experimental results and model validation. Continuum Mech Thermodyn 31:33-45

12. Gregoire TF, Catherine R (2017) Sampling roots to capture plant and soil functions. Functional Ecology 31(8):1506-1518

13. Ghestem M, Veylon G, Bernard A, Vanel Q, Stokes A (2014) Influence of plant root system morphology and architectural traits on soil shear resistance. Plant Soil 377:43-61

14. He XB, Xu YB, Zhang XB et al (2007) Traditional farming system for soil conservation on slope farmland in southwestern China. Soil Tillage Res 94(1):193-200

15. Havaee S, Mosaddeghi MR, Ayoubi S (2015) In situ surface shear strength as affected by soil characteristics and land use in calcareous soils of central Iran. Geoderma 237:137-148

16. Jemberu W, Baartman JEM, Fleskens $L$ et al (2017) Assessing the variation in bund structure dimensions and its impact on soil physical properties and hydrology in Koga catchment. Highlands of Ethiopia Catena 157:195-204

17. Jaime G, Lesley S, Tommaso D, Carlo P (2017) Behavior of RC beams strengthened in shear with FRP and FRCM composites. Engineering Structures 150:830-842

18. Harsh VS, Anita MT (2016) Effect of antecedent soil moisture content on soil critical shear stress in agricultural watersheds. Geoderma $262: 166-173$

19. Li GR, Hu XS, Mao XQ (2013a) Research on mechanics Mechanism and Model of Root-soil interaction of Plants and shrub plants in Loess Area of Northeast Qinghai-Tibetan Plateau. Soil Water Conservation in China 7:37-41

20. Lise P, Prince Z, Jennifer B, Marc L (2018) Enhancing phenotyping and molecular analysis of plant root system using ultrasound aeroponic technology. Current Protocols 3(4):e20078

21. Li Y (2013b) Effects of particle shape and size distribution on the shear strength behavior of composite soils. Bulletin of Engineering Geology the Environment 72:371-381

22. Murielle G, Guillaume V, Alain B et al (2014) Influence of plant root system morphology and architectural traits on soil shear resistance. Plant Soil 377(12):43-61

23. Oliver F, Ingolf K, Julian S, Van SN, Erwin B (2018) Plant diversity and composition of rice field bunds in Southeast Asia. Paddy water environment 16:359-378

24. Raes D, Kafiriti EM, Wellens J, Deckers J, Maertens A, Mugogo S, Dondeyne S, Descheemaeker K (2007) Can soil bunds increase the production of rain-fed lowland rice in south eastern Tanzania? Agricultural Water Management 89:229-235

25. Sun TC, Liu TT, Chu L, Li ZX, Wang TW, Cai CF (2019) Effects of temporal and spatial variations in source-sink landscape patterns on soil erosion and sediment yield from typical watershed in the Three Gorges Reservoir area, China. Acta Ecol Sin 39(20):7476-7492

26. Xing HW, Liu J, Wang LH et al (2010) Friction characteristics of soil-soil interface and root-soil interface of Caragana Intermedia and Salix Psammophila[J]. Tribology 30(1):87-91 (in Chinese with English abstract)

27. Tian J, Cao B, J, J.N., et al., 2015. Direct shear friction test and numerical simulation of soil-soil and root-soil interface of Hedysarum scoparium and Salix psammophila. Transactions of the Chinese Society of Agricultural Engineering (Transactions of the CSAE). 31 (13): 149-156

Page $7 / 11$ 
28. Vietha N, Nhatduc H, Vanbinh D, Hongdang V, Dieu TB (2020) A hybrid computational intelligence approach for predicting soil shear strength for urban housing construction: a case study at Vinhomes Imperia project, Hai Phong city (Vietnam). Engineering with Computers 36(2):1-14

29. Wei J, Shi BL, Li JL, Li SS, He XB (2018) Shear strength of purple soil bunds under different soil water contents and dry densities: A case study in the Three Gorges Reservoir Area, China. Catena 166:124-133

30. Wei J, Shi BL, Li JL (2016) Response of soil shear strength to soil water content in purple soil slope cropland bunds. Transactions of the Chinese Society of Agricultural Engineering (Transactions of the CSAE) 32(20):153-160

31. Wang JJ, Zhang HP, Wen HB et al (2015) Shear strength of an accumulation soil from direct shear test. Marine Georesources Geotechnology 33(2):183190

32. Walle J, Jantiene EMB, Luuk F, Yihenew GS, Coen JR (2017) Assessing the variation in bund structure dimensions and its impact on soil physical properties and hydrology in Koga catchment, Highlands of Ethiopia. Catena. 157, 195-204

33. Wang SS, Shi DM, Jiang GG et al (2012) Analysis of soil structure stability and corrosion resistance of slop land bio-band in purple hilly area. J Soil Water Conserv 26(6):31-35,40. (in Chinese with English abstract)

34. Yves LB, Ivan P, Catherine R, Jerome N, James M, Sylvain H, Mario V, Alexia S (2018) Soil aggregate stability in Mediterranean and tropical agroecosystems: effect of plant roots and soil characteristics. Plant Soil 424(1):303-317

35. Yang Y, Chen L, Li N (2016a) How gauge length and loading rate influence the root tensile strength of Betula platyphylla. J Soil Water Conserv 71(6):460466

36. Yao K, An DL, Wang W, Li N, Zhang C, Zhou A (2020) Effect of nano-MgO on mechanical performance of cement stabilized silty clay. Marine Georesources Geotechnology 38(2):250-255

37. Zhang CB, Chen LH, Liu YP, Ji XD, Liu XP (2010) Triaxial compression test of soil-root composites to evaluate influence of roots on soil shear strength. Ecological Engineering 36:19-26

38. Zhang YG, Zhang WQ, Hui L (2018) Analysis of deformation characteristics and stability mechanisms of typical landslide mass based on the field monitoring in the Three Gorges Reservoir, China. Journal of Earth Science. 128(9)

39. Zhao DH, Ji XD, Zhang X et al (2021) Friction performance of root-soil interface of Betula platyphylla in Northwestern Hebei Province, China. Transactions of the Chinese Society of Agricultural Engineering (Transactions of the CSAE) 37(3):124-131. (in Chinese with English abstract)

\section{Tables}

Table 1. The comparison of different friction interface effect on direct shear friction characteristics

\begin{tabular}{lccl}
\hline Interface type & $\begin{array}{c}\text { Mean of friction } \\
\text { angle } /\left(^{\circ}\right)\end{array}$ & $\begin{array}{c}\text { Mean of cohesion } \\
\text { stress } / \mathrm{kPa}\end{array}$ & Friction coefficient \\
\hline Soil-soil interface & $22.81 \pm 4.59 \mathrm{~b}$ & $13.22 \pm 2.21 \mathrm{a}$ & $0.42 \pm 0.09 \mathrm{~b}$ \\
\hline $\begin{array}{l}\text { Root-soil interface of } \\
\text { Crabgrass }\end{array}$ & $37.00 \pm 5.44 \mathrm{a}$ & $11.87 \pm 10.60 \mathrm{a}$ & $0.76 \pm 0.14 \mathrm{a}$ \\
\hline $\begin{array}{l}\text { Root-soil interface of } \\
\text { Barnyard grass }\end{array}$ & $31.63 \pm 7.98 \mathrm{a}$ & $13.46 \pm 6.35 \mathrm{a}$ & $0.64 \pm 0.20 \mathrm{a}$ \\
\hline $\begin{array}{l}\text { Root-soil interface of } \\
\text { Goosegrass }\end{array}$ & $45.01 \pm 6.81 \mathrm{a}$ & $3.24 \pm 1.05 \mathrm{~b}$ & $1.03 \pm 0.21 \mathrm{a}$ \\
\hline
\end{tabular}

Table 2. Numerical simulation result of direct shear friction test for different frictional interface

\begin{tabular}{|c|c|c|c|c|c|c|c|c|c|c|}
\hline \multirow[b]{2}{*}{$\begin{array}{l}\text { Vertical } \\
\mathrm{load} / \mathrm{kPa}\end{array}$} & \multicolumn{3}{|c|}{ Soil-soil interface } & \multicolumn{3}{|c|}{$\begin{array}{l}\text { Root-soil interface of } \\
\text { Crabgrass }\end{array}$} & \multicolumn{3}{|c|}{$\begin{array}{l}\text { Root-soil interface of } \\
\text { Barnyard grass }\end{array}$} & \multirow{2}{*}{$\begin{array}{l}\text { Root-so } \\
\text { Goose? } \\
\text { Experin } \\
\text { values } \\
\text { shear } \\
\text { strengt }\end{array}$} \\
\hline & $\begin{array}{l}\text { Experimental } \\
\text { values of } \\
\text { shear } \\
\text { strength/kPa }\end{array}$ & $\begin{array}{l}\text { Simulated } \\
\text { values } \\
\text { of shear } \\
\text { strength/kPa }\end{array}$ & $\begin{array}{l}\text { Relative } \\
\text { error/\% }\end{array}$ & $\begin{array}{l}\text { Experimental } \\
\text { values of } \\
\text { shear } \\
\text { strength/kPa }\end{array}$ & $\begin{array}{l}\text { Simulated } \\
\text { values } \\
\text { of shear } \\
\text { strength/kPa }\end{array}$ & $\begin{array}{l}\text { Relative } \\
\text { error/\% }\end{array}$ & $\begin{array}{l}\text { Experimental } \\
\text { values of } \\
\text { shear } \\
\text { strength/kPa }\end{array}$ & $\begin{array}{l}\text { Simulated } \\
\text { values } \\
\text { of shear } \\
\text { strength/kPa }\end{array}$ & $\begin{array}{l}\text { Relative } \\
\text { error/\% }\end{array}$ & \\
\hline 25 & 30.01 & 23.71 & -20.99 & 30.81 & 21.64 & -29.76 & 33.30 & 32.89 & -1.23 & 32.09 \\
\hline 50 & 32.12 & 37.46 & 16.63 & 33.18 & 44.88 & 35.26 & 44.45 & 50.74 & 14.14 & 55.65 \\
\hline 75 & 52.95 & 51.21 & -3.28 & 66.42 & 68.12 & 2.56 & 62.31 & 68.58 & 10.07 & 69.90 \\
\hline 100 & 57.55 & 64.96 & 12.88 & 94.61 & 91.36 & -3.44 & 107.46 & 86.43 & -19.57 & 116.35 \\
\hline 150 & 97.30 & 92.46 & -4.97 & 138.94 & 137.84 & -0.79 & 113.38 & 122.12 & 7.71 & 143.07 \\
\hline
\end{tabular}

Note: $\mathrm{P}$ indicates vertical load; $\mathrm{\tau}$ indicates shear strength; soil moisture is $15 \%$

\section{Figures}



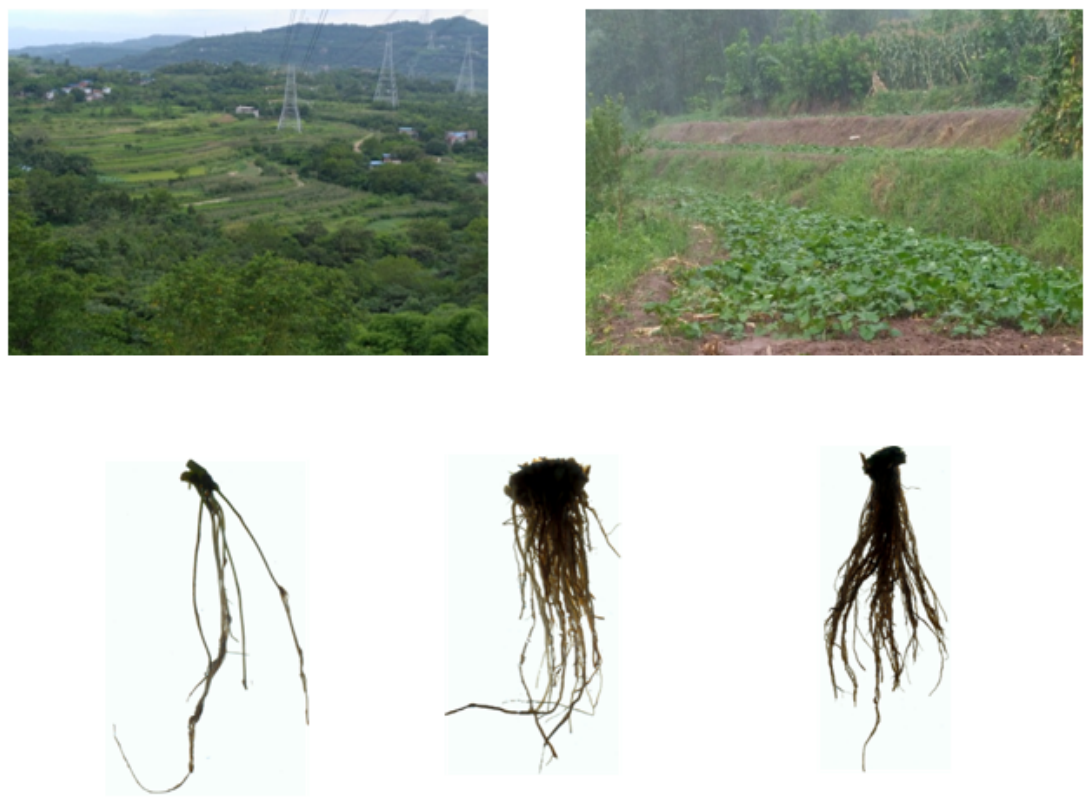
a. crabgrass
b. barnyard grass
c. goosegrass

Figure 1

Schematic diagram of grass root

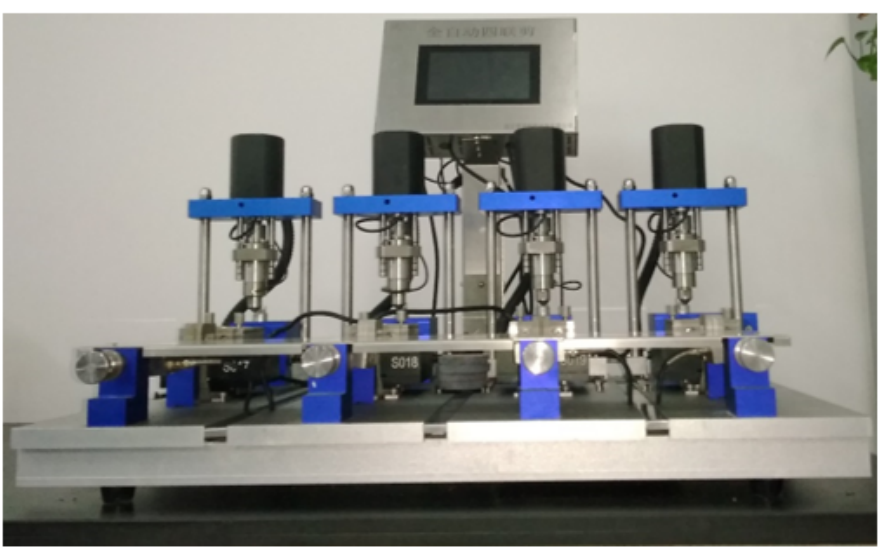

Figure 2

A fully automatic quadruple shear device used in this study 

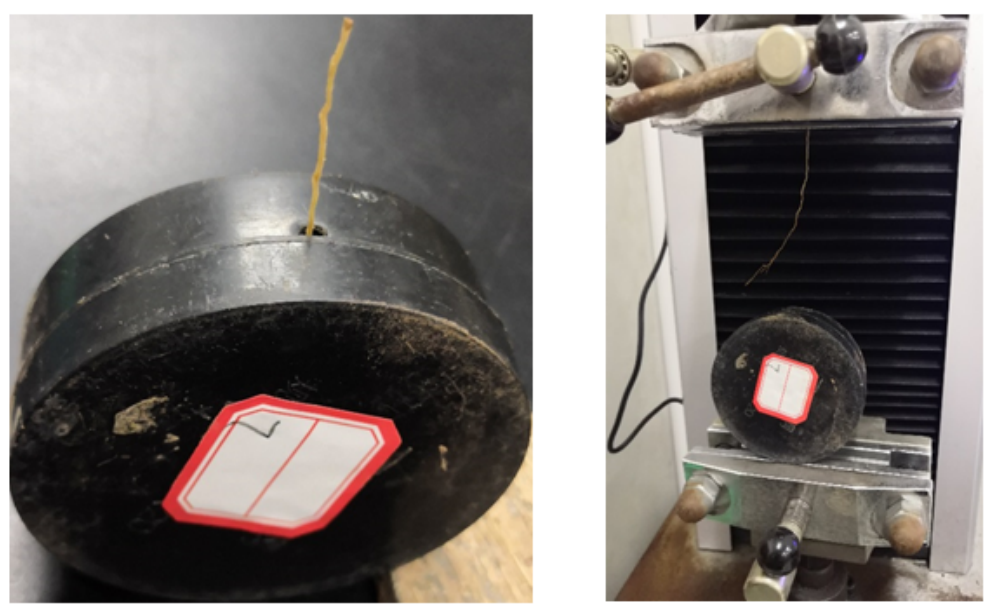

Figure 3

A electronic tension tester (LDS-5A) device used in this study
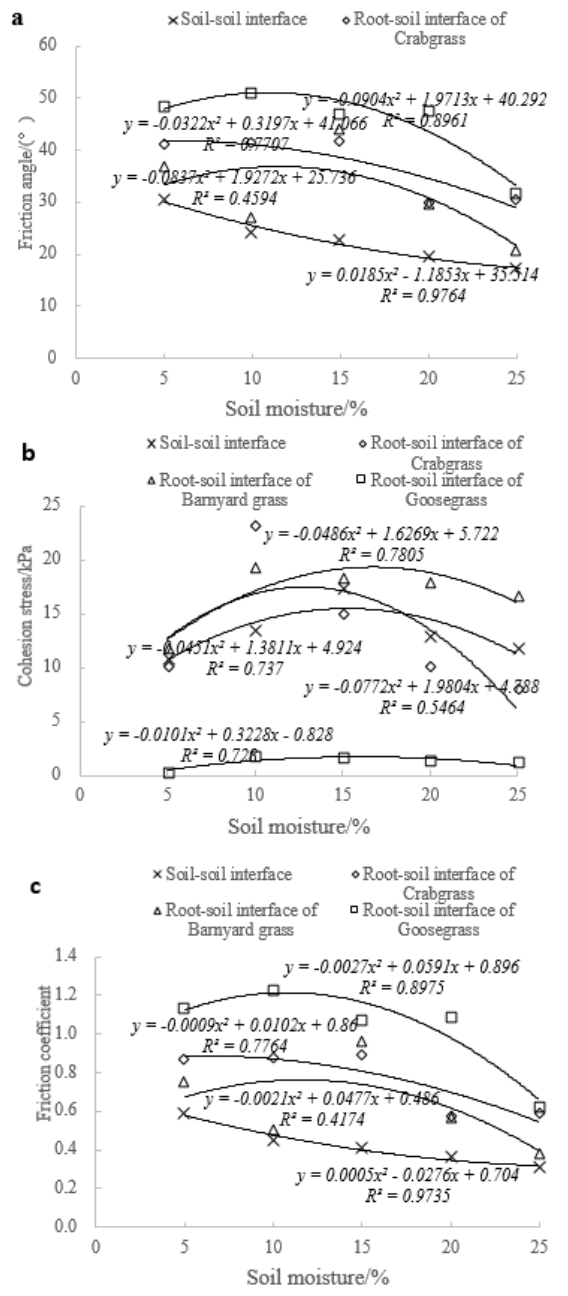

\section{Figure 4}

Relationship between friction characteristics and soil moisture under different friction interface 


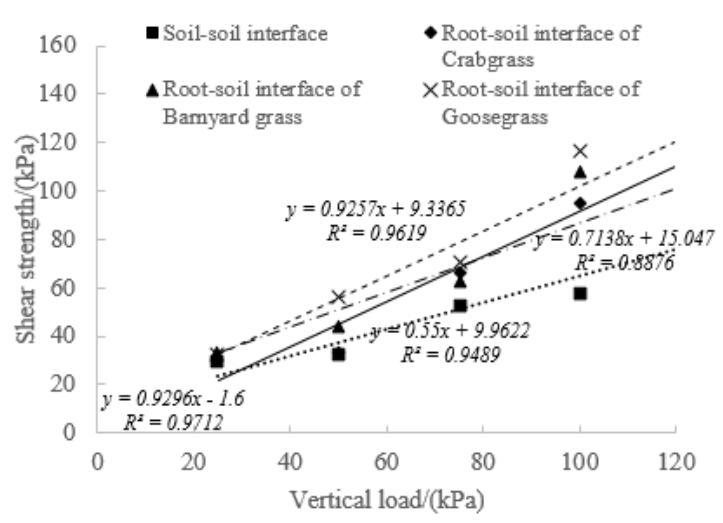

\section{Figure 5}

Relationship between vertical load and shear strength on different friction interface Note: $\mathrm{P}$ indicates vertical load; $\tau$ indicates shear strength; soil moisture is $15 \%$
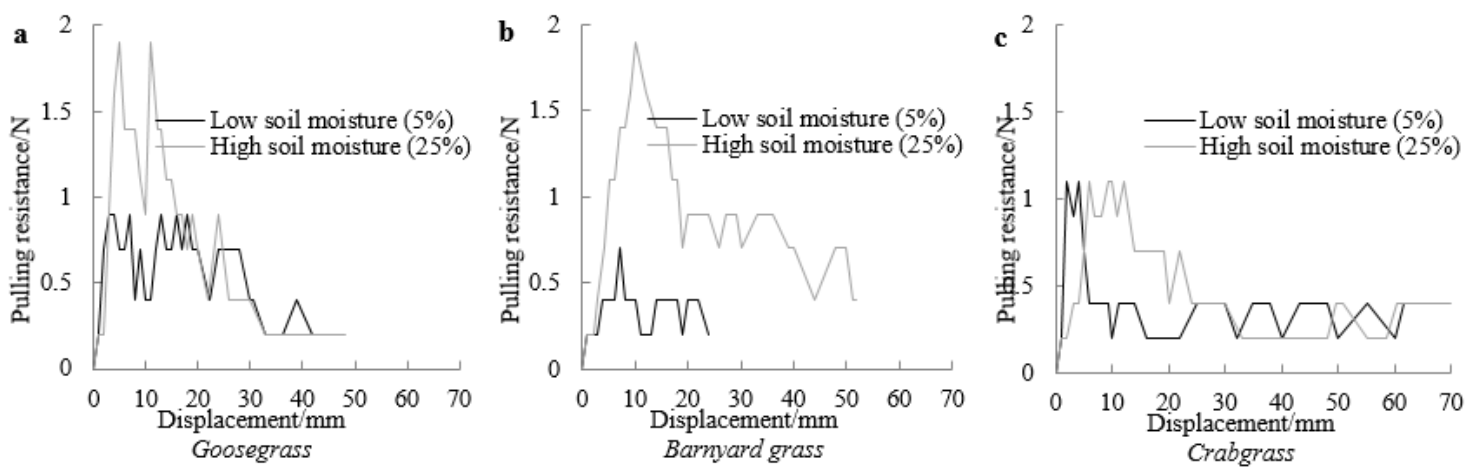

\section{Figure 6}

The relationship between pulling resistance and sliding displacement

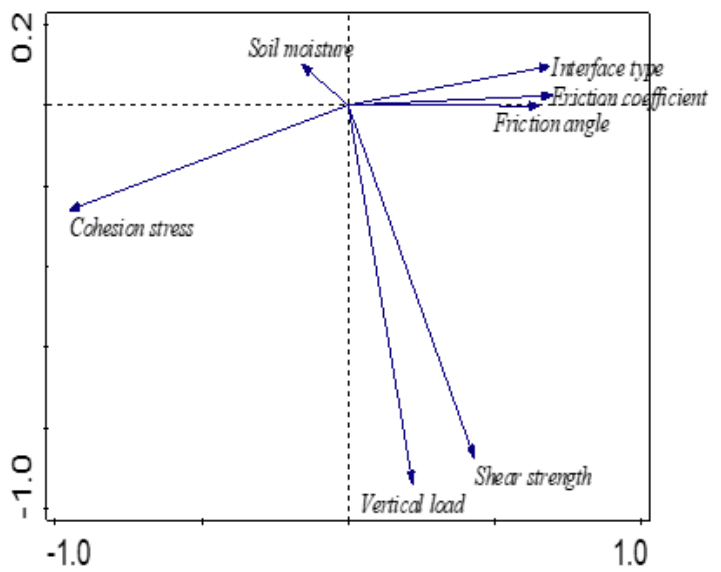

\section{Figure 7}

Analysis of root-soil friction characteristics value and various influencing factors 